\title{
Local Anesthesia Failure Cases with Scorpion Bite History in Third Molar Surgery- A Challenge
}

\author{
Venkata Ramana Murthy $\mathbf{V}^{1^{*}}$, Chandrasekhar Krishnamurti ${ }^{2}$, Jambukeshwar Kumar $\mathbf{B}^{3}$, \\ Boyina Kiran Kumar ${ }^{4}$, T Subbaraju Reddy ${ }^{5}$, Nallamothu Raghuveer ${ }^{6}$ \\ ${ }^{I}$ Reader, Department of Oral and Maxillofacial Surgery, Vishnu Dental College, Bhimavaram, India \\ ${ }^{2}$ Professor, Department of Anesthesiology, NRI Institute of Medical Sciences, Visakhapatnam, India \\ ${ }^{3}$ Senior Lecturer, Department of Oral and Maxillofacial Surgery, Vishnu Dental College, Bhimavaram, India \\ ${ }^{4}$ Senior Lecturer, Department of Oral and Maxillofacial Surgery, Anil Neerukonda Institute of Dental Sciences, \\ Visakhapatnam, India \\ ${ }^{5}$ Reader, Department of Oral and Maxillofacial Surgery, Sri Sai Dental College and Research Centre, \\ Srikakulam, India \\ ${ }^{6}$ Associate Professor, Department of Orthodontics, Batterjee Medical College, India
}

*Corresponding Author: Venkata Ramana Murthy V, Department of Oral and Maxillofacial Surgery, Vishnu Dental College, Bhimavaram, India, Email: murthymaxfac@gmail.com

\begin{abstract}
Patients planned for third molar surgery who were administered conventional intraoral mandibular nerve block were considered. Local anesthesia failure in third molar surgery can be attributed to many causes but, failure due to history of scorpion bite was not reported in the literature in oral and maxillofacial surgeries. On the operative day after obtaining informed consent, local infiltration of the skin on the ventral aspect of the forearm, using, $6 \mathrm{ml}$, $2 \%$ lignocaine with adrenaline, was carried out. Confirming the suspicion, there was no sensory block after the injection, confirmed by pin prick method. Cases reported in the literature were due to failure of spinal anesthesia but not in third molar surgery the female patients also gave a history of spinal anesthesia failure during their deliveries and were operated under general anesthesia.
\end{abstract}

Keywords: scorpion bite, local anesthesia résistance, minor oral surgery.

\section{INTRODUCTION}

Management of pain is an ever challenging task; overcoming the failures of local Anesthesia is one of the concerns in oral and maxillofacial third molar surgical procedures. Local anesthesia injections are widely performed successfully in most of the Oral and Maxillofacial surgical cases, but failures of Anesthesia do occur even after careful injection techniques ${ }^{1}$.

Failures can be attributed to many factors, but failure in patients with history of scorpion bite priory to third molar surgery was not much reported in the literature compared to spinal anesthesia. The scorpion venom is known to affect the pumping mechanism of sodium channels in the nerve fibers, which are involved in the mechanism of action of local anesthetic drugs, it may be responsible for the development of 'resistance' to the action of local anesthetic agents ${ }^{2}$. Local anesthetics are the safest and most effective drugs available for the prevention and the management of pain. Indeed, there are no other drugs that truly prevent pain. Depositing a local anesthetic drug in close proximity to a sensory nerve and clinically adequate pain control will result in essentially all clinical situations.

\section{Materials And Methods}

All the patients with age group between 21-58 yrs reported to the Department of Oral and Maxillofacial surgery who has given history of scorpion bite were included in the study. The total duration of the third molar surgery was expected at 20-40 minutes. The Management of local anesthesia in third molar patient with 
history of scorpion bite is a challenging task, as most of the cases show failure of anesthesia. The patients were given repeated blocks of anesthesia with three different drugs with Lidocaine $2 \%, \quad 1: 200000$ adrenaline, Mepivacaine 3\%, Articaine 4\%, 1:200000 adrenaline with similar onset of action, similar pka values. Patients were evaluated for signs and symptoms of sensory blockade for a period of 30 minutes and the other block were carried out in the same way and was observed for signs of anesthesia. Patients were given left median, ulnar and radial nerve block at the wrist and local infiltration near the anatomical snuff box. There was no sensory or motor block. We report series of 18 cases that had scorpion bite with single/multiple history who were treated with midazolam $1 \mathrm{mg} / 1 \mathrm{ml}$ with incremental dosing and ketamine $2 \mathrm{mg} / \mathrm{kg}$ to achieve adequate anesthesia for a period of 30 minutes.

\section{RESULTS}

All the patients in the study did not show any signs and symptoms of Anesthesia even after repeated local anesthetic blocks with Lidocaine, Mepivicaine, and Articaine. However, 12 patients who had history of single/multiple scorpion bite in the recent times within a year did not show any anesthesia. 6 patients who had scorpion bite more than $2 \mathrm{yrs}$ showed delayed response for the block with Articiane with an average onset of action at 20 minutes and was not responsive to Lidocaine and Mepivicaine. The procedures were completed within 20-26 minutes. Thermal response was not elicited as a part of the study. All the patients who showed failure were all from the same tribal area where incidence of scorpion bite was more and can be attributed to the natural habitat of scorpions.

The cause of the failures may be due to technical inability to achieve block. However, failure that occurs despite of technically correct injection of the correct drug can be disappointing to the surgeon. As the scorpion venom is known to affect the pumping mechanism of sodium channels in the nerve fibers, which are involved in the mechanism of action of local anesthetic drugs, it may be responsible for the development of "resistance" to the action of local anesthetic agents. All the patients were planned prior to the surgery with history of scorpion bite and were treated successfully without any post operative complications.

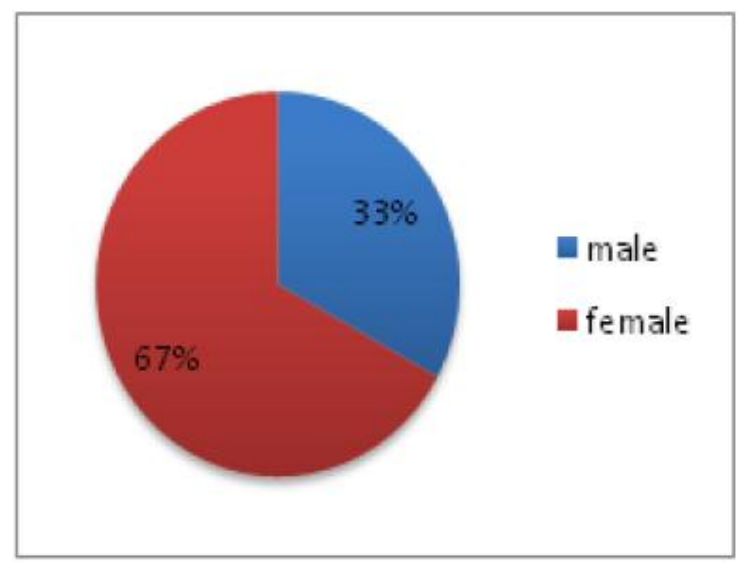

Representation of Patients in the Study

\section{DISCUSSION}

Mandibular block anesthesia or conventional intraoral inferior nerve block has a high success rate, one of the most commonly used block for third molar surgery as well as in achieving anesthesia for most of the procedures in oral and maxillofacial surgery ${ }^{3}$. Vinckier has estimated failure rates of $10 \%$ for inferior alveolar nerve block and $7 \%$ for the rest of anesthetic procedures with only few $\mathrm{ml}$ is required for additional blocks ${ }^{4}$. Wong and Jacobsen had reported that inferior alveolar nerve injections using the conventional technique fail in 5-15\% of cases ${ }^{5}$. However evaluating exact cause of the local anesthesia failure is essential for identification of failed blocks and provides pain free treatments in third molar surgery. Clinician (choice of anesthetic technique) and patient (anatomical, pathological or psychological) related factors play a major role ${ }^{6}$. The underlying cause has to be evaluated careful to ensure painless surgeries. It is important to take into consideration that the anatomy varies with age and development of the facial structures changes over a period with edentualism ${ }^{7}$.

In our country, scorpion bites are a relatively a common phenomenon. The failure of anesthesia due to scorpion bite is not even recorded as a part of medical history which accounts to few cases of local anesthesia failure as explained by competitive antagonism in spinal anesthesia failures $^{8}$. Experiments have shown that these scorpion toxins are modifiers of the gating mechanism of the Na+-channel function, affecting either the inactivation (a-toxins) or the activation (b-toxins) kinetics of the channels. Mostly our study results can also be attributed to the antagonism at the binding site ${ }^{9-14}$. However, 
many authors attribute antagonism as one of the important factor for the failure but, more research at the molecular level has to be conducted to find out the exact cause of failure of anesthesia ${ }^{15-16}$.

Anesthetic response varies among individuals within the same family with different pain threshold. Interestingly, our study found our all the patients belong to a particular tribe had anesthetic failure. In effect, $1 \%$ of the population may refer no response at all, while another $1 \%$ may refer an extraordinary effect, and $70 \%$ tend to respond as expected ${ }^{17}$. Many authors attribute loco regional anesthesia failure to a lack of knowledge or experience that can only be avoided with full knowledge of the anatomy and mechanisms of anesthetic effect ${ }^{18}$. Various methods of pain control have their own merits and demerits ${ }^{19,} 20$. The clinician must choose the most appropriate method in the best interests of the patient while performing the nerve block and providing painless surgical treatment. Even though proper, scientific, skilled professional is mastered in anatomical and patient management concepts, awareness on local anesthetic failure should raise the suspicion of previous history of scorpion bite as the number of cases of local anesthesia failure has been on the rise in oral and maxillofacial surgery $^{21}$.

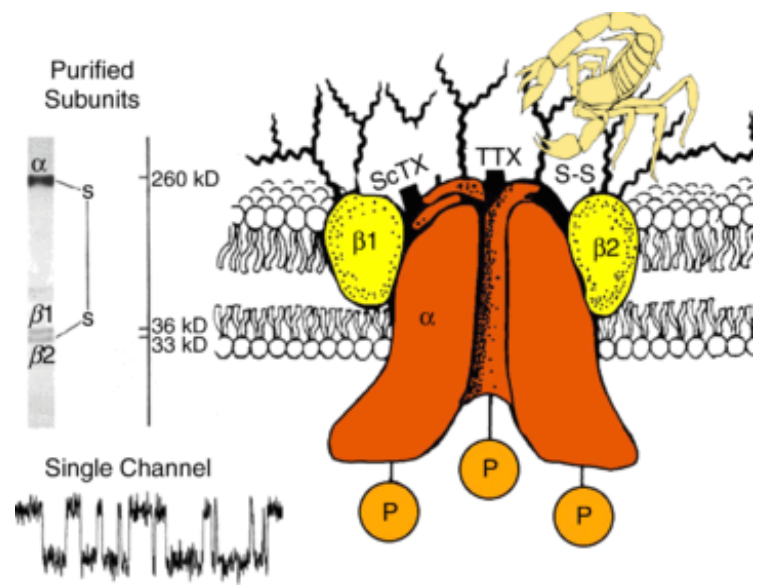

Diagrammatic representation of Scorpion Toxin Mechanism and Inhibition

\section{CONCLUSION}

The management of pain is challenging even after the advent of many recent drugs to combat pain in the present day clinical scenario. Development of many recent techniques to overcome local anesthetic failure in oral and maxillofacial surgery has been mentioned in the literature but, Patients with previous history of scorpion bite need to further evaluated carefully, treatment has to be planned priory with alternate techniques of anesthesia to avoid unnecessary psychological trauma to the patient and educate and bring awareness about the failure of injections among the fraternity and in the patients. We firmly believe, it has immunological basis and the mechanism of this 'resistance' involves possible 'competitive antagonism'. Interestingly the phenomenon is noticed in tribal population which was interesting. Studies have to be performed and further evaluated in the years to come.

\section{REFERENCES}

[1] Trescot AM (2003) Local anaesthetic "resistance". Pain Physician 6(3): 291-293.

[2] Guinard JP, Carpenter RL, Smith HS. A prospective evaluation of the failure rate of spinal anesthesia for transurethral prostatic resection. Eur J Anaesthesiol. 1992Jan;9(1): 713.

[3] Dr. Harsh Rajvanshi, Dr. Sandra Ernest, Dr. Hafsa Effendi, Dr. Navneet Kaur: failure of inferior alveolar nerve block (IANB) and techniques to avoid it; ejbps, 2016, Volume 3, Issue 9, 207-210.

[4] Vinckier F. What is the cause of failure of local anesthesia? Rev Belge Med Dent 2000; 55:4150.

[5] Wong MK, Jacobsen PL. Reasons for local anesthesia failures. J Am Dent Assoc 1992; 123:69-73

[6] Araceli boronat lópez, Miguel peñarrocha diago, Failure of locoregional anesthesia in dental practice. Review of the literature, oral patol oral cir bucal 2006; 11:e510-3.

[7] Singh UK, Layland FC, Prasad R, Singh S. Poisoning in children.4th ed. New Delhi: Jaypee brother'smedical publishers (P) Ltd; 2013.

[8] Guinard JP, Carpenter RL, Smith HS. A prospective evaluation of the failure rate of spinal anesthesia for transurethral prostatic resection. Eur J Anaesthesiol. 1992Jan;9(1): 713.

[9] Butterworth JF 4th, Strichartz GR Molecular mechanisms of local anesthesia: a review.

[10] Son SL, Wong K, Strichartz G : Antagonism by local anesthetics of sodium channel activators in the presence of scorpion toxins: two mechanisms for competitive Inhibition. Anesthesiology 1992 Aug; 77(2):324-35.

[11] Panditrao MM, Panditrao MM, Panditrao AM (2015) Development of Resistance to the Effect of Local Anesthetic Agents Administered Via Various Routes Due to Single or Multiple, Previous Scorpion Bites: A Proposed Hypothesis and Reporting a Yet Unrecognized 
Phenomenon. J Anesth Crit Care Open Access 3(5): 00110. DOI:10.15406/jaccoa.2015.03.00 110

[12] Fettes PD, Jansson JR, Wildsmith JA (2009) Failed spinal anesthesia: Mechanisms, manage ment, and prevention. Br J Anaesth 102(6):739 748.

[13] Raw RM, Nwaneri ER. Spinal anesthetic block failure due to the hyperbaric nature of the chloroprocaine local anesthetic. Ambul Surg 2010

[14] Lourival D. Possani, Baltazar Becerril, Muriel Delepierre and Jan Tytgat: Scorpion toxins specific for $\mathrm{Na}^{+}$-channels; Eur. J. Biochem. 264, 287士300 (1999) q FEBS 1999

[15] Panditrao MM, Panditrao MM, Khan MI, Yadav N. Does scorpion bite lead to development of resistance to the effect of local anesthetics? Indian J Anaesth. 2012 Nov; 56 (6):575-8.

[16] Wright SN, Wang SY, Wang GK. Lysine point mutations in $\mathrm{Na}+$ channel D4-S6 reduce inactivated channel block by local anesthetics. Mol Pharmacol. 1998 Oct; 54(4):733-9.

[17] 10. Ragsdale DS, McPhee JC, Scheuer T, Catterall WA. Molecular determinants of state- dependent block of $\mathrm{Na}+$ channels by local anesthetics. Science. 1994 Sep 16; 265(5179): 1724-8.

[18] Batas D, Nejad MR, Prabhu PK. Resistance to local anesthetics: A case report. Published; 26thJanuary2007.Availablefrom:http://www.bj a.oxfordjournals.org/cgi/qa-display/short/brjana _el; 1576. [Last accessed 2015 Aug 20]

[19] Liem EB, Joiner TV, Tsueda K, Sessler DI (2005) Increased sensitivity to thermal pain and reduced subcutaneous lidocaine efficacy in redheads. Anesthesiology 102(3): 509-514.

[20] Liem EB, Lin CM, Suleman MI, Doufas AG, Gregg RG, et al. (2004) Anesthetic requirement is increased in redheads. Anesthesiology101 (2): 279-283

[21] Munhall RS, Sukhani R, Winnie AP (1988) Incidence and etiology of failed spinal anesthetics in a university hospital: a prospective study. Anesth Analg 67(9): 843848.

Citation: Venkata Ramana Murthy V, Chandrasekhar Krishnamurti, Jambukeshwar Kumar B, Boyina Kiran Kumar, T Subbaraju Reddy, Nallamothu Raghuveer. Local Anesthesia Failure Cases with Scorpion Bite History in Third Molar Surgery- A Challenge. ARC Journal of Anesthesiology. 2017; 2(2):7-10. doi: dx.doi.org/10.20431/2455-9792.0202003.

Copyright: (C) 2017 Authors. This is an open-access article distributed under the terms of the Creative Commons Attribution License, which permits unrestricted use, distribution, and reproduction in any medium, provided the original author and source are credited. 